\title{
Analisis Pengaruh Rotasi dan Mutasi Kerja Terhadap Kinerja Karyawan di KJKS BMT Anda Salatiga
}

\author{
Nur Aini \\ nuraini440@gmail.com \\ Institut Agama Islam Negeri Salatiga
}

Tulus

titisansamudera@gmail.com

Institut Agama Islam Negeri Salatiga

\begin{abstract}
This study aims to determine whether job rotation and work mutation influence employee performance at BMT KJKS Anda Salatiga. Samples in this study are 31 respondents. This research uses primary datas which are collected through interview and questionnaires. Multiple regression analysis is used as analytical method in this research. The research shows that job rotation influences employee performance partially but work mutation does not. Job rotation and work mutation does not influence employee performance simultaneously.
\end{abstract}

Key words: Job rotation, work mutation, Employee performence

\section{Abstrak}

Penelitian ini bertujuan untuk mengetahui apakah terdapat pengaruh rotasi dan mutasi kerja terhadap kinerja karyawan di KJKS BMT ANDA Salatiga.Populasi yang digunakan dalam penelitian ini adalah karyawan KJKS BMT ANDA Salatiga sebanyak 37 karyawan. Sampel dalam penelitian ini sebanyak 31 responden. Jenis data dalam penelitian ini adalah primer. Metode pengumpulan data melalui wawancara dan kuesioner. Metode analisis yang digunakan adalah regresi linear berganda. Hasil penelitian membuktikan bahwa secara parsial rotasi berpengaruh terhadap kinerja karyawan. Mutasi 
kerja secara parsial tidak berpengaruh terhadap kinerja karyawan dan rotasi kerja dan mutasi kerja secara simultan tidak berpengaruh terhadap kinerja karyawan.

Kata Kunci: Rotasi Kerja, Mutasi Kerja, Kinerja Karyawan.

\section{Pendahuluan}

Semenjak perekonomian Indonesia diramaikan oleh kegiatan perbankan yang berbasis syariah, maka mulai bermunculan lembaga keuangan yang berbasis syariah. Salah satunya adalah koperasi syariah atau yang disebut dengan Koperasi Jasa Keuangan Syariah (KJKS). UndangUndang Nomor 35 Pasal 1 tahun 2007 menyatakan bahwa Koperasi Jasa Keuangan Syariah adalah koperasi yang kegiatan usahanya bergerak di bidang pembiayaan, investasi, dan simpanan sesuai pola syariah.

Menurut Mathis dan Jackson dalam Indrayati (2014: 3) kinerja karyawan individual merupakan faktor utama penentu keberhasilan organisasional dan mereka mempengaruhi produktivitas dan kinerja organisasional secara signifikan. Menurut Lasa dalam Susilawati (2013: 3) untuk mengembangkan sumber daya manusia, selain dengan pendidikan dan pelatihan dapat juga dilakukan dengan rotasi kerja dan magang. Rotasi kerja dimaksudkan untuk mengurangi kejenuhan, memberikan kesegaran kerja, serta menambah keterampilan dan pengalaman kepada karyawan. Dengan demikian apabila ada karyawan yang cuti atau tidak masuk kerja, tugas dan pekerjaan karyawan yang bersangkutan dapat dilaksanakan oleh karyawan lain.

Selain rotasi, sistem mutasi sangat penting karena individu sebagai pekerja akan merasa dihargai karena tidak disia-siakan oleh instansi atau perusahaan, tetapi lebih menempatkan tenaga kerja pada tempat yang tepat. Hal ini dapat memberikan dorongan kepada individu tersebut agar prestasinya meningkat sesuai dengan harapan instansi atau perusahaan (Judas, 2014: 1220). Mutasi merupakan kegiatan memindahkan tenaga kerja dari satu tempat kerja ke tempat kerja lain. Akan tetapi, mutasi tidak selamanya sama dengan pemindahan. Mutasi meliputi kegiatan memindahkan tenaga kerja, pengoperan tanggung jawab, pemindahan status ketenagakerjaan dan 
Analisis Pengaruh Rotasi dan Mutasi Kerja terhadap Kinerja Karyawan...

sejenisnya. Adapun pemindahan hanya terbatas pada mengalihkan tenaga kerja dari suatu tempat ke tempat lain. Jadi, mutasi lebih luas ruang lingkupnya ketimbang pemindahan.

Alasan peneliti melakukan penelitian tentang rotasi dan mutasi kerjadikarenakan rotasiselain berfungsi bagi pengembangan sumber daya manusia, rotasi juga diyakini dapat memberikan banyak manfaat lain bagi organisasi, rotasi dapat mencegah timbulnya kebosanan dan dapat mengurangi absennya karyawan. Menurut Manggarsih dalam Nurlatifah (2009: 20) manfaat tidak langsung dari rotasi bagi organisasi adalah ketika karyawan memiliki keterampilan lebih luas pada bidang pekerjaan, sehingga lebih mudah dalam penjadwalan kerja, mengatur cuti karyawan dan beradaptasi terhadap perubahan. Di samping itu kemampuan KJKS beradaptasi terhadap perubahan merupakan hal yang sangat dibutuhkan untuk bertahan pada kondisi sekarang ini, di mana perubahan merupakan suatu hal yang biasa terjadi dan berlangsung lebih cepat dari waktu ke waktu. Mengenai mutasi, peneliti memilih mutasi karena peneliti sependapat dengan Judas (2014: 1220) bahwa sistem mutasi sangat penting karena individu sebagai pekerja akan merasa dihargai karena tidak disia-siakan oleh instansi atau perusahaan, tetapi lebih menempatkan tenaga kerja pada tempat yang tepat. Hal ini dapat memberikan dorongan kepada individu tersebut agar prestasinya meningkat sesuai dengan harapan instansi atau perusahaan.Dari uraian di atas, maka pokok masalah yang akan dikaji dalam penelitian ini adalah mengenai pengaruh rotasi kerja terhadap kinerja karyawan KJKS BMT ANDASalatiga; pengaruh mutasi kerja terhadap kinerja karyawan KJKS BMT ANDA Salatiga; pengaruhrotasi dan mutasi kerja secara bersama-sama terhadap kinerja karyawan KJKS BMT ANDA Salatiga.

\section{Landasan Teori}

Menurut Mathis dan Jackson dalam Indrayati (2014: 36) rotasi pekerjaan adalah proses pemindahan seseorang dari satu pekerjaan ke pekerjaan yang lain. Sebuah teknik yang digunakan untuk mengurangi kemonotonan suatu rutinitas yang dilakukan karyawan. Biasanya setiap perusahaan memiliki kebijakan-kebijakan sendiri dalam penerapan waktu rotasi pekerjaan. Ada yang berkala (mingguan, bulanan dan tahunan) dan 
tidak berkala. Keunggulan dari rotasi pekerjaan sendiri adalah mengembangkan kapabilitas seorang karyawan dalam melakukan beberapa pekerjaan yang berbeda.

Tujuan rotasi kerja dinyatakan oleh Kaymaz dalam Indrayati (2014: 36) bahwarotasi pekerjaan akan mengurangi kebosanan, mempersiapkan karyawan untuk sistem manajemen yang lebih baik, meningkatkan produktivitas, dan meningkatkan pengetahuan dan keterampilan. Tujuan dan manfaat rotasi pekerjaan tidak hanya dirasakan langsung oleh karyawan, tetapi perusahaan juga merasakan manfaat tidak langsung karena karyawan rentang akan keterampilan dan manajemen yang lebih luas dan lentur dalam penjadwalan kerja, penyesuaian diri karyawan atas perubahan, dan mengisi kekosongan personalia.Selain itu menurut Juwita dalam Indrayati (2014: 37) rotasi pekerjaan dapat membantu manajer dalam menghadapi terjadinya ketidakhadiran dan perputaran karyawan sehingga dapat mengisi kekosongan posisi dengan cepat.

Menurut Hasibuan dalam Indrayati (2014: 37) rotasi pekerjaan memiliki manfaat sebagai berikut: (a) Meningkatkan produktivitas; (b) Menciptakan keseimbangan antara tenaga dengan komposisi jabatan; (c) Memperluas atau menambah pengetahuan karyawan; (d) Menghilangkan rasa jenuh atau bosan karyawan terhadap pekerjaan; (e) Memberikan perangsang agar karyawan mau meningkatkan karir yang lebih tinggi; (f) Untuk pelaksanaan hukuman atau sanksiatas pelanggaran-pelanggaran yang dilakukan karyawan; (g) Alat pendorong atau spirit kerja meningkat melalui persaingan-persaingan terbuka; (h) Untuk memberikan pengakuanpengakuan atas prestasinya; (i) Untuk tindakan pengamanan yang lebih baik; (j) Untuk menyesuaikan pekerjaan dengan kondisi fisik karyawan; (k) Untuk mengatasi perselisihan antar sesama karyawan.

Selanjutnya, menurut Sofa dalam Nurhadis (2012: 34) mutasi merupakan fungsi pengembangan karyawan, karena tujuan utamanya adalah untuk meningkatkan efisiensi dan efektifitas kerja dalam organisasi yang bersangkutan. Umumnya mutasi merupakan tindak lanjut dari penilaian prestasi kerja para karyawan. Dari penilaian prestasi kerja akan diketahui kecakapan seorang karyawan dalam menyelesaikan uraian pekerjaan yang dibebankan kepadanya. Tidak kurang kritik pedas yang dilontarkan kepada 
Analisis Pengaruh Rotasi dan Mutasi Kerja terhadap Kinerja Karyawan...

bagian kekaryawanan menyangkut masalah mutasi, seperti ketidakadilan ataupun keterbukaan pihak pengambil keputusan dalam proses ini.

Pigors dan Mayers dalam Nurhadis (2012: 34) mengemukakan 5 macam mutasi dilihat dari segi tujuannya yaitu:

\section{Production Transfer}

Adalah pengalih tugasan seorang karyawan dari satu bagian ke bagian lain secara horizontal, di mana di satu bagian tersebut keperluan akan pekerjaan bertambah, atau ke bagian lain di mana terdapat lowongan pekerjaan karena ada karyawan yang berhenti atau pensiun.

2. Replacement Transfer

Adalah pengalih tugasan seorang karyawan yang sudah lama dinasnya ke jabatan lain secara horizontal untuk menggantikan karyawan lain yang masa dinasnya lebih sedikit atau diberhentikan.

\section{Remedial Transfer}

Adalah pengalih tugasan seorang karyawan ke jabatan atau pekerjaan lain baik pekerjaannya sama atau tidak atas permintaan karyawan yang bersangkutan.

\section{Shift Transfer}

Adalah pengalih tugasan seorang karyawan yang sifatnya horizontal dari satu regu lain sedangkan pekerjaan tetap sama namun jam kerja berbeda. Umumnya pembagian kerja terbagi dalam 3 shift. Yaitu shift satu, shift dua, dan shift tiga.

5. Versality Transfer

Adalah pengalih tugasan seorang karyawan ke jabatan atau pekerjaan lainnya secara horizontal agar karyawan yang bersangkutan dapat melakukan pekerjaan atau ahli dalam berbagai bidang pekerjaan.

Menurut Hasibuan dalam Nurhadis (2012: 36) tujuan mutasi sebagai bahan berpikir:

1. Untuk meningkatkan produktivitas kerja karyawan

2. Untuk memperluas atau menambah pengetahuan karyawan

3. Untuk menghilangkan rasa bosan karyawan terhadap pekerjaannya

4. Untuk menyesuaikan pekerjaan dengan kondisi fisik karyawan 
5. Untuk menciptakan keseimbangan antara tenaga kerja dengan komposisi pekerjaan atau jabatan

6. Untuk mengatasi perselisihan antara sesama karyawan

Kata kinerja merupakan suatu hasil kerja dari seorang karyawan dalam pencapaian tujuan organisasi yang diharapkan (Indrayati, 2014: 20). Menurut Rivai dan Basri dalam Indrayati (2014: 39) ragam kinerja dipengaruhi dua hal yaitu perubahan lingkungan eksternal dan lingkungan internal. Ragam kinerja karena perubahan lingkungan eksternal akan lebih sulit diperkirakan karena tidak dapat dikontrol oleh perusahaan. Faktor-faktor eksternal yang mempengaruhi adalah letak geografis, etos kerja, etika kerja, kinerja perekenomian, hukum, politik, dan sosial. Ragam kinerja yang dipengaruhi oleh letak geografis berhubungan dengan waktu kerja, waktu senggang, jenis tunjangan yang ditawarkan oleh perusahaan, tingkat stress, atau masalah pribadi yang muncul di tempat kerja. Ragam kinerja yang dipengaruhi oleh etos kerja dan etika kerja menggambarkan sikap umum karyawan dan pekerjaannya. Ragam kinerja yang dipengaruhi oleh kinerja perekonomian akan merefleksi pada kemampuan karyawan dalam memenuhi kebutuhan hidupnya sesuai dengan yang diharapkannya.

Ragam kinerja yang dipengaruhi oleh sisi hukum dalam bentuk peraturan perundang-undangan, dari sisi politik akan berpengaruh pada kualitas perencanaan kebutuhan SDM karena kondisi politik yang selalu goyah dan berimplikasi pada timbulnya keguncangan bisnis, kemudian dari sisi sosial budaya masyarakat bisa memberi perbedaan etos kerja. Sedangkan ragam kinerja karena perubahan lingkunganinternal meliputi perubahan kondisi perusahaan dan karyawan. Ragam kinerja yang dipengaruhi oleh kondisi perusahaan yang sehat dan kurang sehat dilihat dari sisi efisiensi akan berpengaruh terhadap permintaan atau kebutuhan SDM. Ragam kinerja yang dipengaruhi oleh kondisi karyawan itu sendiri dapat dilihat dari segi perilaku, penguasan teknologi, ragam kebutuhan karyawan, tingkat kehadiran, dan perputaran karyawan yang akan berpengaruh pada produktivitas. Kedua perubahan lingkungan tersebut saling berkaitan satu sama lain karena dapat membantu manajer dan spesialis SDM dalam meramalkan tipe-tipe SDM yang dibutuhkan dan yang tersedia untuk memenuhi tujuan-tujuan perusahaan. 
Analisis Pengaruh Rotasi dan Mutasi Kerja terhadap Kinerja Karyawan...

Menurut Indrayati (2014: 21) tingkatan kinerja terbagi dari kinerja individu dan kinerja kelompok atau organisasi.Menurut Nitasari dalam Indrayati (2014: 21) "Manajemen kinerja merupakan suatu proses yang dirancang untuk menghubungkan tujuan organisasi dengan tujuan individu, sehingga tujuan tersebut bertemu". Dengan demikian kinerja karyawan yang tinggi diharapkan dapat memberi sumbangan yang sangat berarti bagi kinerja dan kemajuan perusahaan.

Menurut Indrayanti (2014: 23) kinerja karyawan individual merupakan faktor utama yang menentukan keberhasilan organisasional. Karyawan yang melakukan pekerjaan akan mempengaruhi kinerja dan produktivitas perusahaan secara signifikan. Menurut Mathis dan Jackson (2011: 42) kinerja individual dipengaruhi oleh tiga faktor: (1) Kemampuan individual untuk melakukan pekerjaan tersebut, (2) Tingkat usaha yang dicurahkan, dan (3) Dukungan organisasi. Komponen kinerja individual yang dipengaruhi oleh kemampuan individual adalah bakat, minat, dan faktor kepribadian. Usaha yang dicurahkan meliputi motivasi, etika kerja, kehadiran, dan rancangan tugas. Dukungan organisasi komponennya yaitu pelatihan dan pengembangan, peralatan dan teknologi, standar kinerja, dan manajemen dan rekan kerja. Kinerja individual ditingkatkan sampai tingkat di mana ketiga faktor tersebut ada dalam diri karyawan. Apabila salah satu faktor tersebut dihilangkan atau dikurangi maka kinerja karyawan akan mengalami penurunan. Kemudian akan mempengaruhi penurunan kinerja perusahaan.

Dari sekian uraian yang telah kami tuliskan pada bab dan sub bab di at as sehingga diperoleh hipotesis sebagai berikut:

H1: Rotasi kerja berpengaruh positif dan signifikan terhadap kinerja karyawan.

H2: Mutasi kerja berpengaruh positif dan signifikan terhadap kinerja karyawan.

H3 : Rotasi dan mutasi kerja secara bersama-sama berpengaruh positif dan signifikan terhadap kinerja karyawan. 


\section{Metode Penelitian}

1. Populasi dan Sampel

Dalam penelitian ini, populasi yang digunakan adalah karyawan KJKS BMT ANDA Salatiga yang berjumlah 37 orang, yang kami peroleh dari hasil wawancara di KJKS BMT ANDA Salatiga. Berdasarkan jumlah populasi tersebut, dengan menggunakan tingkat kesalahan adalah 7\%, maka diperoleh sampel dalam penelitian ini sebanyak 31 (Bawono, 2006: 29).

2. Data dan sumber data

Penelitian ini menggunakan data primer yang diperoleh dengan menyusun kuesioner yang kemudian kami bagikan kepadan karyawan BMT ANDA Salatiga selaku responden penelitian, untuk mengetahui tanggapan responden mengenai rotasi dan mutasi kerja yang dilakukan pada BMT ANDA Salatiga.

3. Teknik Analisis Data

Penelitian ini menggunakan pengujian reliabilitas, validitas, dan uji asumsi klasik (multikolinearitas, heterokedastisitas, dan normalitas). Pengujian hipotesis dengan menggunakan uji $\mathrm{t}$ dan uji $\mathrm{F}$.

\section{Analisis Data}

\section{Identitas Responden}

Sebelum dilakukan analisis, terlebih dahulu kami akan menjelaskan mengenai data-data responden yang digunakan sebagai sampel dalam penelitian ini, yang akan kami ambil dari seluruh karyawan KJKS BMT ANDA Salatiga.

a) Jenis Kelamin Responden

Tabel 1. Jenis Kelamin Responden

\begin{tabular}{|c|c|c|c|}
\hline No & Jenis Kelamin & Responden & Prosentase \\
\hline 1 & Laki-laki & 17 Responden & $55 \%$ \\
\hline 2 & Perempuan & 14 Responden & $45 \%$ \\
\hline \multicolumn{2}{|r|}{ 'T('I'^I } & 31 Responden & $100 \%$ \\
\hline
\end{tabular}

Sumber: Data primer yang diolah, 2015 
Dari data di atas, dapat diketahui bahwa responden yang kami ambil didominasi oleh karyawan laki-laki/perempuan. Jumlah karyawan lakilaki sebanyak 17 responden (55\%), dan karyawan perempuan sebanyak 14 responden $(45 \%)$.

b) Usia Responden

Tabel 2

Usia Responden

\begin{tabular}{|c|c|c|c|}
\hline No & Usia & Responden & Prosentase \\
\hline 1 & $<20$ Tahun & 2 Responden & $6,45 \%$ \\
\hline 2 & $20-25$ Tahun & 6 Responden & $19,35 \%$ \\
\hline 3 & $26-30$ Tahun & 7 Responden & $22,60 \%$ \\
\hline 4 & $>30$ Tahun & 10 Responden & $32,25 \%$ \\
\hline 5 & Tidak diisi & 6 Responden & $19,35 \%$ \\
\hline \multicolumn{2}{|c|}{ TOTAL } & 31 Responden & $100 \%$ \\
\hline
\end{tabular}

Sumber: Data primer yang diolah, 2015

Dari tabel di atas, dapat diketahui bahwa karyawan KJKS BMT ANDA Salatiga yang dijadikan sebagai sampel, didominasi usia 30 tahun yaitu sebesar $32,25 \%$, diikuti usia 26-30 tahun dengan prosentase $22,6 \%$, sementara untuk rentang usia 20-25 tahun dan yang tidak mencatumkan usia memiliki prosentase $19,35 \%$, sedangkan usia 20 tahun memiliki prosentase $6,45 \%$.

\section{Pengujian Kualitas Data}

a) Uji Reliabilitas

Pengujian reliabilitas suatu angket dikatakan reliabel jika jawaban seseorang terhadap pertanyaan konsisten dari waktu ke waktu (Bawono, 2006: 63). Uji ini dilakukan terhadap seluruh item atau pertanyaan dalam penelitian ini dengan menggunakan acuan nilai Cronbach Alpha. Dengan asumsi bahwa daftar pertanyaan yang diuji akan dikatakan reliabel bila nilai Cronbach Alphae" 0,60. Adapun hasil uji reliabilitas yang diperoleh dalam penelitian ini adalah sebagai berikut: 
Tabel 3

Uji Reliabilitas Variabel Rotasi (X1)

\begin{tabular}{|c|c|c|}
\hline Cronbach`sAlpha & Cronbach`s Alpha Based onStandarized Items & N of items \\
\hline, 685 &, 667 & 7 \\
\hline
\end{tabular}

Sumber: Data primer yang diolah, 2015

Dari keterangan tabel di atas dapat diketahui jika variabel rotasi memiliki Cronbach's Alpha 0,685 atau > 0,60. Dengan demikian variabel rotasi dapat dikatakan reliabel.

Tabel 4

Uji Reliabilitas Variabel Mutasi Kerja (X2)

\begin{tabular}{|c|c|c|}
\hline Cronbach'sAlpha & Cronbach's Alpha Based onStandarized Items & N of items \\
\hline, 665 &, 659 & 4 \\
\hline
\end{tabular}

Sumber: Data primer yang diolah, 2015

Dari keterangan tabel di atas dapat diketahui jika variabel mutasi kerja memiliki Cronbach's Alpha 0,665 atau > 0,60. Dengan demikian variabel mutasi kerja dapat dikatakan reliabel.

Tabel 5

Uji Reliabilitas Variabel Kinerja Karyawan (Y)

\begin{tabular}{|c|c|c|}
\hline Cronbach'sAlpha & Cronbach's Alpha Rased on Standarized Items & N of items \\
\hline 812 &, 813 & 5 \\
\hline
\end{tabular}

Sumber: Data primer yang diolah, 2015

Dari keterangan tabel di atas dapat diketahui jika variabel kinerja karyawan memiliki Cronbach'sAlpha 0,812 atau >0,60. Dengan demikian variabel kinerja karyawan dapat dikatakan reliabel. 
b) Uji Validitas

Suatu angket dikatakan valid, jika pertanyaan pada suatu angket mampu untuk mengungkapkan sesuatu yang diukur oleh angket tersebut (Bawono, 2006: 68). Berikut hasil pengujian validitas terhadap angket:

Tabel 6

Hasil Uji Validitas

\begin{tabular}{|c|c|c|c|c|}
\hline Variabel & Item & $\begin{array}{c}\text { Corrected item total } \\
\text { Correlation } \\
\text { (R hilung) }\end{array}$ & R Tabel & Keterangan \\
\hline \multirow{7}{*}{ Rotasi } & Butir 1 & 360 & \multirow{7}{*}{0,2366} & Valid \\
\hline & Butir 2 & .413 & & Valid \\
\hline & Butir 3 &, 485 & & Valid \\
\hline & Butir 4 &, 792 & & Valid \\
\hline & Butir 5 &, 703 & & Valid \\
\hline & Butir 6 &, 705 & & Valid \\
\hline & Butir 7 & .555 & & Valid \\
\hline \multirow{4}{*}{ Mutasi } & Butir 9 & 433 & \multirow{4}{*}{0,2366} & Valid \\
\hline & Butir 10 & .673 & & Valid \\
\hline & Butir 11 &, 791 & & Valid \\
\hline & Butir 12 &, 750 & & Valid \\
\hline \multirow{5}{*}{$\begin{array}{c}\text { Kinerja } \\
\text { Karyawan }\end{array}$} & Butir 13 &, 805 & \multirow{5}{*}{0,2366} & Valid \\
\hline & Butir 14 &, 775 & & Valid \\
\hline & Butir 15 &, 845 & & Valid \\
\hline & Butir 16 &, 656 & & Valid \\
\hline & Butir 17 &, 703 & & Valid \\
\hline
\end{tabular}

Sumber: Data primer yang diolah, 2015

Dari data di atas dapat diketahui bahwa masing-masing item memiliki $\mathrm{r}$ hitung > r tabel yang diketahui sebesar 0,2366 dan bernilai positif. Dengan demikian butir pertanyaan tersebut dinyatakan valid.

\section{Hasil Uji Asumsi Klasik}

Uji Asumsi Klasik merupakan tahapan penting dalam melakukan analisis regresi, dalam penelitian ini digunakan persamaan matematis sebagai berikut:

$$
\mathrm{Y}=\beta_{0}+\beta_{1} \mathrm{X}_{1 \mathrm{i}}+\beta_{2} \mathrm{X}_{2 \mathrm{i}}+\mathrm{e}
$$


a. Hasil Uji Multikolinieritas

Uji multikolinieritas digunakan apabila terdapat lebih dari satu variabel independen, untuk mengetahui ada tidaknya korelasi variabel independen. Adapun hasil hasil uji statistik multikolinearitas yang diperoleh dalam penelitian adalah sebagai berikut:

Tabel 7

Uji Multikolinearitas

\begin{tabular}{|l|r|r|r|r|}
\hline Model & R & R Square & \multicolumn{1}{|c|}{$\begin{array}{c}\text { Adjusted R } \\
\text { Square }\end{array}$} & $\begin{array}{l}\text { Std Error of the } \\
\text { Estimate }\end{array}$ \\
\hline 1 & $.409^{\mathrm{a}}$ & .167 & .108 & .57269 \\
\hline
\end{tabular}

a. Predictors: (Constant), X2, X1X1=X2

Tabel 8

Model Summary

\begin{tabular}{|l|r|r|r|r|}
\hline Model & R & R Square & \multicolumn{1}{|c|}{$\begin{array}{c}\text { Adjusted R } \\
\text { Square }\end{array}$} & $\begin{array}{c}\text { Std. Error of the } \\
\text { Estimate }\end{array}$ \\
\hline $\mathbf{1}$ & $.005^{\mathrm{a}}$ & .000 & -.034 & .478 .54 \\
\hline
\end{tabular}

a. Predictors: (Constant), X2

- X2=X1

Tabel 9

Model Summary

\begin{tabular}{|c|r|r|r|r|}
\hline Model & R & R Square & \multicolumn{1}{c|}{$\begin{array}{c}\text { Adjusted R } \\
\text { Square }\end{array}$} & $\begin{array}{c}\text { Std. Frror of the } \\
\text { Estimate }\end{array}$ \\
\hline 1 & $.005^{4}$ & .000 & -.034 & .69380 \\
\hline
\end{tabular}

a. Predictors: (Constant), X1

Tabel 10

\begin{tabular}{|c|c|c|c|}
\hline No & PERSAMAAN & $\mathbf{R}^{2}$ & KETERANGAN \\
\hline 1. & $\mathrm{X} 1=\mathrm{X} 2$ & 0,000 & Tidak ada Multikolinicritas \\
\hline 2. & $\mathrm{X} 2=\mathrm{X} 1$ & 0,000 & T'idak ada Multikolinierilas \\
\hline \multicolumn{3}{|r|}{ Nilai R $\mathbf{R}^{2}$ dari regresi utama $=\mathbf{0 , 1 6 7}$} \\
\hline
\end{tabular}


Berdasarkan hasil output dengan SPSS maka diketahui $\mathrm{R}^{2}$ dari masing-masing regresi parsial besarnya $<\mathrm{R}^{2}$ regresi utama yaitu 0,167 sehingga dapat disimpulkan bahwa tidak terjadi multikolinearitas pada persamaan regresi, sehingga memenuhi asumsi dalam persamaan regresi yang baik.

b) Hasil Uji Heteroskendastisitas

Uji Heteroskendastisitas bertujuan untuk menguji apakah dalam model regresi terjadi ketidaksamaan variants. Pada penelitian ini teknik pendeteksian ada tidaknya heteroskendastisitas menggunakan grafik scatterplot antara ZPRED (nilai prediksi variabel dependen) dan SRESED (residualnya). Untuk mendeteksi grafik scatterplot tersebut, jika pola yang dihasilkan beraturan (gelombangnya melebar dan menyempit), hal ini cenderung ada gejala heteroskendastisitas. Tetapi jika polanya tidak beraturan ini cenderung tidak ada gejala penyakit heteroskendastisitas (Bawono, 2006: 134). Adapun hasil uji statistik heteroskendastisitas yang diperoleh dalam penelitian ini adalah sebagai berikut:

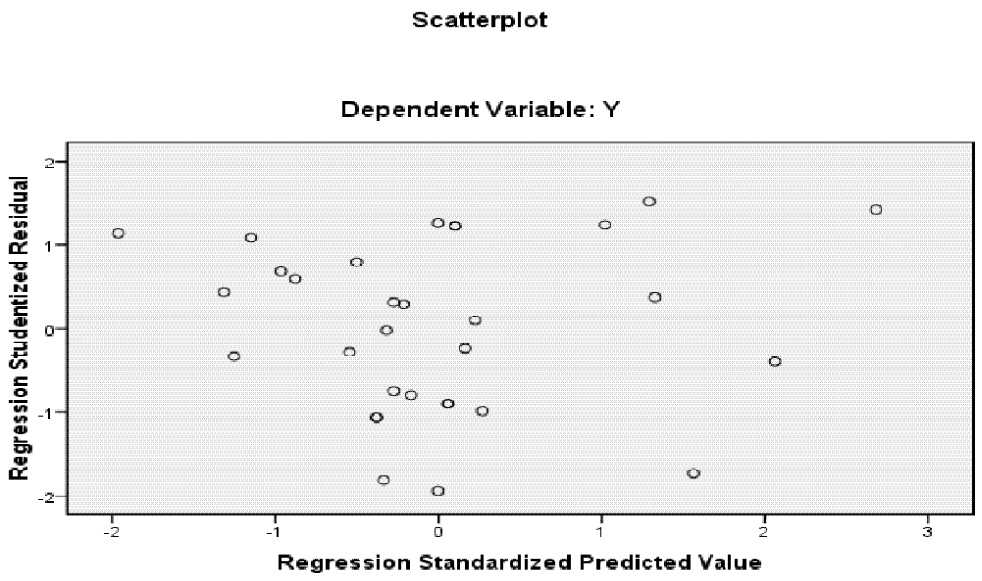

Sumber: Data primer yang diolah, 2015

\section{Gambar 1 Uji Heteroskendasitisitas}

Berdasarkangambar scatterplot diatas dapat kita lihat bahwa plot tidak membentuk pola tertentu atau data menyebar secara acak. Hal ini menunjukkan bahwa tidak ada gejala heteroskendastisitas pada data, sehingga asumsi persamaan regresi yang baik terpenuhi. 
c) Hasil Uji Normalitas

Uji ini dilakukan untuk menguji apakah data variabel dependen dan independen yang kita pakai berdistribusi normal atau tidak. Apabila data menyebar mengikuti garis diagonal maka asumsi normalitas terpenuhi. Adapun uji normalitas dalam penelitian ini adalah sebagai berikut:

Normal P-P Plot of Regression Standardized Residual

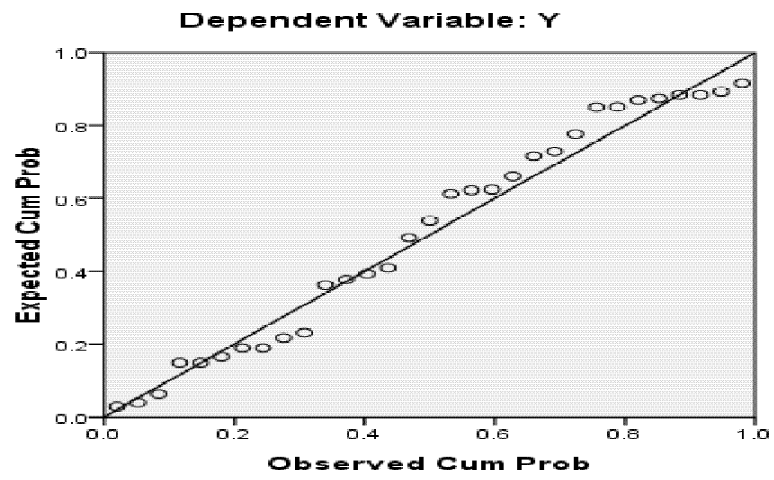

Sumber: Data primer yang diolah, 2015

\section{Gambar 2 Grafik Uji Normalitas}

Berdasarkan gambar scatterplit di atas dapat dilihat bahwa data dari persamaan regresi menyebar mengikut garis diagonal, sehingga dapat disimpulkan bahwa asumsi normalitas terpenuhi.

\section{Uji Statistik}

a) Uji $t_{\text {test }}$ (uji secara Individual)

Uji parameter individual dilakukan terhadap variabel independen (rotasi dan mutasi kerja) dengan hipotesis sebagai berikut:

H1 : Rotasi kerja berpengaruh positif dan signifikan terhadap kinerja karyawan.

H2 : Mutasi kerja berpengaruh positif dan signifikan terhadap kinerja karyawan.

Setelah diolah dengan aplikasi SPSS akhirnya didapatkan hasil output sebagai berikut: 
Tabel 11

Hasil Uji Statistik t

Coefficients $^{\mathrm{a}}$

\begin{tabular}{|c|c|c|c|c|c|c|c|c|}
\hline & \multicolumn{8}{|c|}{ Coefficients $^{a}$} \\
\hline & \multirow{2}{*}{ Model } & \multicolumn{2}{|c|}{$\begin{array}{l}\text { Unstandardized } \\
\text { Coefficients }\end{array}$} & \multirow{2}{*}{$\begin{array}{l}\text { Standardized } \\
\text { Coeflicients } \\
\text { Bela }\end{array}$} & \multirow[b]{2}{*}{$\mathrm{T}$} & \multirow[b]{2}{*}{ Sig. } & \multicolumn{2}{|c|}{ Collinearity Statistics } \\
\hline & & B & Sld. Error & & & & Tolerance & VIF \\
\hline & (Constant) & 1.566 & .917 & & 1.707 & .099 & & \\
\hline \multirow[t]{2}{*}{1} & $\mathrm{X} 1$ & 471 & 222 & .365 & 2.118 & .043 & 1.000 & 1.000 \\
\hline & $\mathrm{X} 2$ & .165 & .153 & .185 & 1.075 & .291 & 1.000 & 1.000 \\
\hline \multicolumn{3}{|c|}{ a. Dependent Variable: $Y$} & & & & & & \\
\hline
\end{tabular}

a. Dependent Variable: Y

Sumber: Data primer yang diolah, 2015

Berdasarkan hasil pengolahan didapatkan nilai t hitung variabel rotasi sebesar 2,118 (lebih besar dari t tabel yang diketahui sebesar 1,3125 ) dengan signifikasi 0,043 di mana nilai tersebut kurang dari nilai alpha 0,05 , sehingga memberikan keputusan ada pengaruh yang positif dan signifikan variabel rotasi terhadap variabel kinerja karyawan. Sedangkan t hitung variabel mutasi kerja sebesar 1,075 (lebih kecil dari t tabel yang diketahui sebesar 1,3125) dengan signifikansi 0,291 di mana nilai tersebut lebih besar dari nilai alpha 0,05 , sehingga memberikan keputusan tidak ada pengaruh yang signifikan antara variabel mutasi kerja terhadap variabel kinerja karyawan dalam penelitian ini.

Kemudian pada tabel diatas menunjukkan bahwa nilai constant sebesar 1,566 serta 0,471 untuk variabel rotasi, dan 0,165 untuk variabel mutasi kerja, sehingga didapat persamaan regresi sebagai berikut: $\mathrm{Y}=$ $1,566+0,471 \mathrm{X} 1+0,165 \mathrm{X} 2+\mathrm{e}$.

Apabila rotasi kerja (X1) dan mutasi kerja (X2) bernilai nol (0), maka kinerja karyawan (Y) bernilai 1,566. Sehingga dapat ditarik kesimpulan bahwa meskipun rotasi dan mutasi kerja yang dilakukan oleh 
KJKS BMT ANDA Salatiga tidak baik, kinerja karyawan tetap ada dikarenakan ada faktor lain yang tidak teridentifikasi.

$\mathrm{X} 1: 0,471$

Bahwa jika rotasi kerja (X1) mengalami peningkatan 1 satuan sedangkan mutasi kerja (X2) konstan atau tidak ada atau sebesar 0, maka kinerja karyawan (Y) akan mengalami peningkatan sebesar 0,471, dengan asumsi ceteris paribus.

b) Uji $F_{\text {test }}$ (uji secara serempak)

Uji ini dilakukan untuk mengetahui apakah variabel independen (rotasi dan mutasi kerja) secara bersama-sama mempengaruhi variabel dependen (kinerja karyawan). Hasil uji simultan atau $\mathrm{F}$ test dapat dilihat pada tabel ANNOVA berikut ini:

Tabel 12

Hasil Uji Simultan (F test)

ANOVA $^{b}$

\begin{tabular}{|l|r|r|r|r|r|}
\hline \multicolumn{1}{|c|}{ Model } & Sum of Squares & Df & Mean Square & F & \multicolumn{1}{c|}{ Sig. } \\
\hline Regression & 1.844 & 2 & .922 & 2.811 & $.077^{\mathrm{a}}$ \\
\hline Residual & 9.183 & 28 & .328 & & \\
\hline Total & 11.027 & 30 & & & \\
\hline
\end{tabular}

Sumber: Data primer yang diolah, 2015

Pada tabel tersebut menunjukkan nilai signifikansi menunjukkan 0,077 di mana nilai tersebut lebih besar dari 0,05 berarti bahwa variabel independen (rotasi dan mutasi kerja) secara bersama-sama tidak mempengaruhi variabel independen (kinerja karyawan).

c) Uji $\mathrm{R}^{2}$ (koefisien determinasi)

Uji koefisien determinasi mempunyai fungsi untuk menjelaskan sejauh mana kemampuan variabel independen dalam hal ini adalah rotasi 
dan mutasi kerja, dalam mempengaruhi variabel dependen yang dalam penelitian ini adalah kinerja karyawan, serta seberapa kuat antara kedua variabel tersebut.

Tabel 13

Hasil Uji Koefisien Determinasi $\mathrm{R}^{2}$

Model Summary

\begin{tabular}{|c|r|r|r|c|}
\hline Model & R & R Square & $\begin{array}{c}\text { Adjusted R } \\
\text { Square }\end{array}$ & $\begin{array}{l}\text { Std. Error of the } \\
\text { Estimate }\end{array}$ \\
\hline 1 & $.409^{\mathrm{a}}$ & .167 & .108 & .57269 \\
\hline
\end{tabular}

a. Predictors: (Constant), X2, X1

Sumber: Data primer yang diolah, 2015

Dari hasil output pada tabel tersebut menunjukkan koefisien determinasi $\left(\mathrm{R}^{2}\right)$ sebesar 0,167 , ini artinya bahwa kontribusi variabel independen menjelaskan atau mempengaruhi variabel dependen sebesar $16,7 \%$, sedangkan sisanya sebesar $83,3 \%$ dijelaskan atau dipengaruhi oleh variabel lain di luar model.

\section{Penutup}

Berdasarkan hasil temuan penelitian yang kami temukan, setelah melalui tahap pengumpulan data, pengolahan data, analisis data mengenai pengaruh rotasi dan mutasi kerja terhadap kinerja karyawan KJKS BMT ANDA Salatiga, maka dapat ditarik kesimpulan sebagai berikut:

1. Pengaruh rotasi kerja terhadap kinerja karyawan

Rotasi kerja berpengaruh secarapositif dan signifikan terhadap kinerja karyawan secara parsial. Hal ini dapat dilihat dari hasil t hitung 2,118 > t tabel (1,3125). Hasil uji hipotesis mengatakan bahwa Ha diterima dan Ho ditolak. Artinya ada pengaruh yang positif dan signifikan antara rotasi terhadap kinerja karyawan di KJKS BMT ANDA Salatiga. 
2. Pengaruh mutasi kerja terhadap kinerja karyawan

Mutasi kerja tidak berpengaruh terhadap kinerja karyawan secara parsial. Hal ini dapat dilihat dari hasil t hitung 1,075 t tabel $(1,3125)$. Hasil uji hipotesis mengatakan bahwa Ho diterima dan Ha ditolak. Artinya tidak ada pengaruh yang positif dan signifikan antara mutasi kerja tehadap kinerja karyawan di KJKS BMT ANDA Salatiga.

3. Pengaruh rotasi kerja dan mutasi kerja secara bersama-sama terhadap kinerja karyawan

Rotasi kerja dan mutasi kerja secara bersama-sama tidak mempengaruhi kinerja karyawan.Hal ini tergambar dari hasil pembahasan dan diperoleh hasil nilai signifikansi sebesar 0,077 di mana nilai tersebut lebih besar dari 0,05 berarti bahwa variabel independen (rotasi dan mutasi kerja) secara bersama-sama tidak mempengaruhi variabel independen (kinerja karyawan).

\section{Daftar Pustaka}

Bawono, Anton. 2006. “Multivariate Analysis dengan SPSS”. Salatiga: STAIN Salatiga Press.

Indrayati, Monic Aprilia. 2014. “Analisis Pengaruh Rotasi Pekerjaan dan Motivasi Kerja terhadap Kinerja Karyawan melalui Kepuasan Kerja pada PT. Bank Tabungan Negara (Persero) Tbk. Kantor Cabang Semarang". Skripsi. Fakultas Ekonomika dan Bisnis. Universitas Diponegoro Semarang.

Judas, Agnetha. 2014. "Mutasi dan Promosi Jabatan Pengaruhnya terhadap Prestasi Kerja Karyawan pada Kanwil Ditjen Kekayaan Negara Suluttenggo dan Maluku Utara di Manado". Jurnal Fakultas Ekonomi dan Bisnis. Universitas Sam Ratulangi Manado.

Nurhadis. 2012. "Pengaruh Mutasi dan Budaya Organisasi terhadap Kinerja Guru SD (Studi Kasus pada Kecamatan Pelepat dan Kecamatan Pelepat Ilir Kabupaten Bungo)". Tesis Program Pascasarjana. Universitas Terbuka Jambi.

Nurlatifah. 2009. "Pengaruh Rotasi Kerja terhadap Kinerja Pustakawan di Perpustakaan Universitas Gadjah Mada”.Skripsi. Fakultas Adab. Universitas Islam Negeri Sunan Kalijaga Yogyakarta. 
Susilawati. 2013. "Pengaruh Rotasi Kerja Terhadap Kinerja Karyawan Perpustakaan di UPT Perpustakaan Institut Seni Indonesia Yogyakarta”. Skripsi. Fakultas Adab dan Ilmu Budaya. Universitas Islam Negeri Sunan Kalijaga Yogyakarta.

Yuafi, Hamdan dkk. 2014. "Pengaruh Kinerja Layanan Bank Syariah Mandiri Cabang Salatiga terhadap Keputusan Menjadi Nasabah Bagi Mahasiswa Perbankan Syariah S1 STAIN Salatiga (Studi Kasus Pelayanan Ketika Pembayaran SPP/ UKT Semester Ganjil Tahun Akademik 2014/2015)". Penelitian Jurusan Syariah \& Ekonomi Islam. STAIN Salatiga. 